\title{
RE-EXAMINATION OF THE FAULT MODEL FOR THE NIIGATA EARTHQUAKE OF 1964
}

\author{
Katsuyuki $\mathrm{ABE}^{*}$ \\ Department of Earth and Planetary Sciences, \\ Massachusetts Institute of Technology, \\ Cambridge, Massachusetts, U.S.A.
}

(Received July 8, 1975)

\begin{abstract}
The source mechanism of the Niigata earthquake of $1964\left(M_{s} \approx 7.5\right)$ is re-studied in detail on the basis of the $\mathrm{P}$ wave first motion, $\mathrm{S}$ wave polarization angle, long-period surface wave, aftershock, precise levelling, tide gage, and tilt measurement data. The long-period surface wave data and geodetic data are interpreted consistently in terms of a thrust fault reaching the earth's surface and having a dip of $56^{\circ}$ toward $N 81^{\circ} \mathrm{W}$, a dimension of $80 \mathrm{~km}$ (length) $\times 30 \mathrm{~km}$ (width), and an average dislocation of $3.3 \mathrm{~m}$. The seismic moment is $3.2 \times 10^{27}$ dyne. $\mathrm{cm}$. The stress drop is estimated to be 70 bars. This value is not very different from the stress drops obtained for moderate to large shallow earthquakes which occurred in the Japanese islands. The fault plane geometry obtained here is slightly different from that determined from the $P$ wave first motions. Combining this result with the weak beginning of the initial $\mathrm{P}$ waves, we may interpret the entire faulting process in terms of a multiple faulting which consists of the two events: the initial localized rupture is followed, after about $4 \mathrm{sec}$, by the major faulting, which is responsible for the excitation of long-period waves.
\end{abstract}

\section{Introduction}

The Niigata earthquake of June $16,1964\left(M_{s} \approx 7.5\right)$, is unique among large earthquakes; it has provided a wealth of invaluable data on the unusual pre-seismic deformation as well as the dynamics of faulting (e.g., TsuBoKaWA et al., 1964; Dambara, 1973; Scholz et al., 1973; Earthouake Research Institute, 1964; Japan Meteorological Agency, 1965; Kawasumi, 1968). However, our knowledge of the fault dimensions is still incomplete; for example, the width of the fault was somewhat arbitrarily assumed as $20 \mathrm{~km}$ (AKI, 1966b; Hirasawa, 1965).

This uncertainty in fault width throws a serious doubt on the accuracy of the previous estimate of the stress drop by AkI (1966b). His estimate, 126 bars, is the largest of all the values heretofore determined for moderate to

* Present address: Department of Geophysics, Faculty of Science, Hokkaido University, Sapporo, Japan. 
large shallow earthquakes which occurred in the Japanese islands (e.g., ABE, 1972c, 1975). Inasmuch as recent studies indicate that the stress drop is proportional to the seismic ground motion in the vicinity of an earthquake fault (ABE, 1975), a reliable re-determination of the stress drop for the Niigata earthquake is desirable.

This paper presents a detailed analysis of seismic and geodetic data obtained for this particular earthquake in an attempt to re-determine various fault parameters. The Niigata earthquake provides a particularly favorable case for this kind of study because detailed data are now available on the fault plane solution (AKr, 1966a, b; HIRASAWA, 1965), aftershock distribution (Kayano, 1968, 1973), precise levelling survey (Geographical Survey INStITUte of JAPAN, 1966, 1970), tilt measurement (Yahiko Crustal MoveMENTS OBSERVATORY, 1973), and various field observations (e.g., NAKAMURA et al., 1964; HATORI, 1965). We shall first determine the fault geometry using world-wide data of long-period surface waves.

\section{Seismic Waves}

\subsection{Radiation pattern of surface waves}

AKI (1966a) used the amplitude and phase spectra of G2 waves in source studies. In this study we employ the wave-form equalization method described in KANAMORI (1970). Multiple surface waves G2, G3, R2 and R3 are recovered from the standard 30-100 long-period seismograms obtained at World-Wide Standard Seismograph Network stations (WWSSN). The 38 traces for Love waves and 32 traces for Rayleigh waves are equalized in frequency domain for instrumental magnification, attenuation, and dispersion to a standard epicentral distance of $\frac{5}{2} \pi$. The phase velocities and attenuation coefficients are identical to those used in KANAMORI (1970). The equalized spectra are then Fourier-transformed back to time domain.

The equalized seismograms are shown in Figs. 1 and 2 with the threeletter station abbreviations. These traces correspond to G3 and R3 that would have been observed if the stations with the standard 30-100 seismograph having a magnification of 1500 had been located at a distance of $\pi / 2$. The circular plots at the center show the radiation pattern of the maximum trace amplitudes; closed circles show the equalization of G3 and R3, and open circles show the equalization of $G 2$ and R2. These presentations for G3 and R3 can be compared directly with similar presentations given in KANAMORI (1971) and $A B E(1972 a, b, c)$. In the following section we shall determine the force geometry of the source and the seismic moment. 


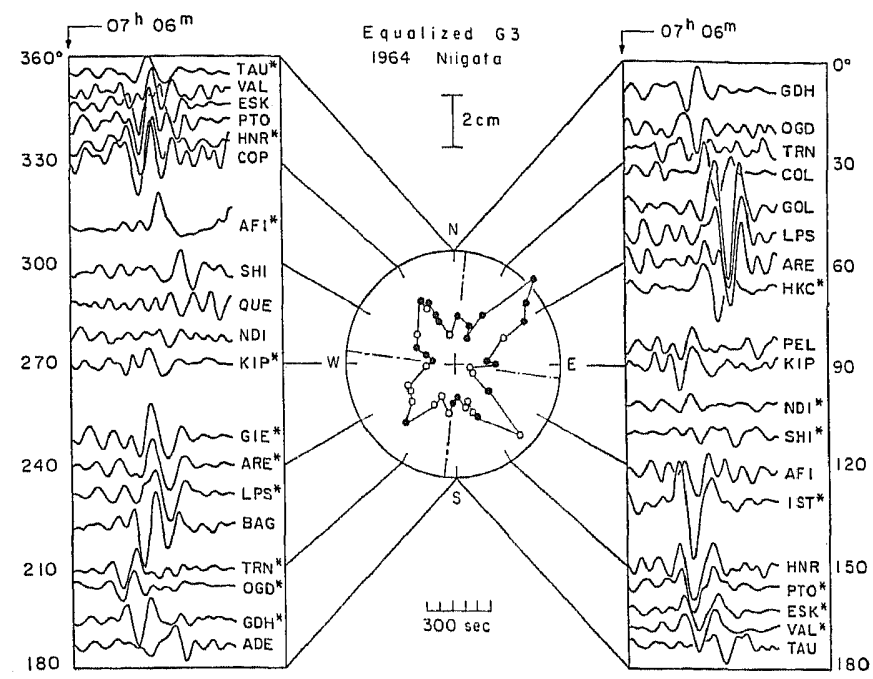

Fig. 1. Love waves (G3) equalized to $\Delta=\frac{5}{2} \pi$ for the Niigata earthquake of June 16,1964 . The vertical scale gives the amplitude on the standard $30-100$ seismogram with a magnification of 1500 . The counterclockwise motion around the epicenter is taken upward on the trace. For stations with an asterisk and open circles in the central circle, the equalization is made for G2. For others, the equalization is made for $\mathrm{G} 3$.

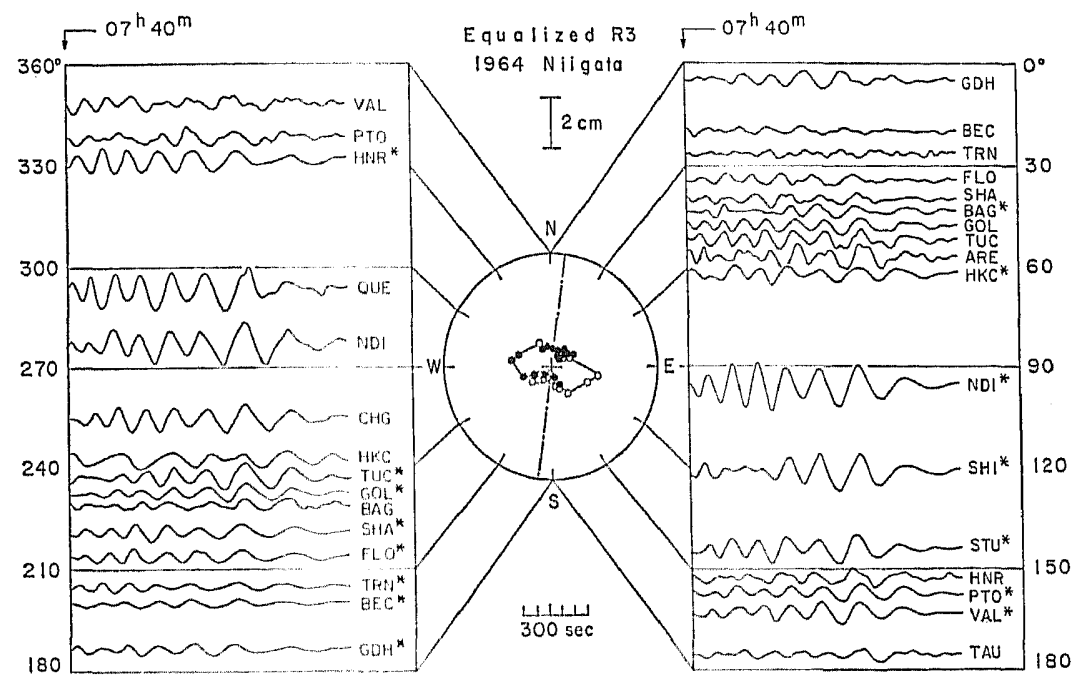

Fig. 2. Rayleigh waves (R3) equalized to $\Delta={ }_{2}^{5} \pi$ for the Niigata earthquake of June 16,1964 . The vertical scale gives the amplitude on the standard 30-100 seismogram with a magnification of 1500 . Upward motion on the trace shows upward ground motion. For stations with an asterisk and open circles in the central circle, the equalization is made for R2. For others, the equalization is made for R3. 


\subsection{Interpretation}

The important features in the equalized seismograms are: (1) the radiation pattern is four-lobed for Love waves and two-lobed for Rayleigh waves; (2) the nodal directions of Love and Rayleigh waves almost coincide with each other; (3) the maximum amplitude of Love waves is slightly larger than that of Rayleigh waves. As well known, these observations can be interpreted in terms of a double-couple source. In this study we determine detailed source geometry by combining the surface and body wave data.

Figure 3 shows the directions of the first motions of $\mathrm{P}$ waves and the polarization angles of $S$ waves on the Wulff grid. The lower half of the focal sphere is projected. The $\mathrm{P}$ wave data are based on the readings of the longperiod WWSSN seismograms and on the Seismological Bulletin of the Japan Meteorological Agency. The $S$ wave data are the polarization angles obtained by HiRASAWA (1965).

We first determine the nodal planes using the $P$ wave and surface wave data. The first motions can determine well only one steeply dipping nodal plane (dip direction $\phi=290^{\circ}$; dip angle $\delta=70^{\circ}$ ). Because of the unfavorable

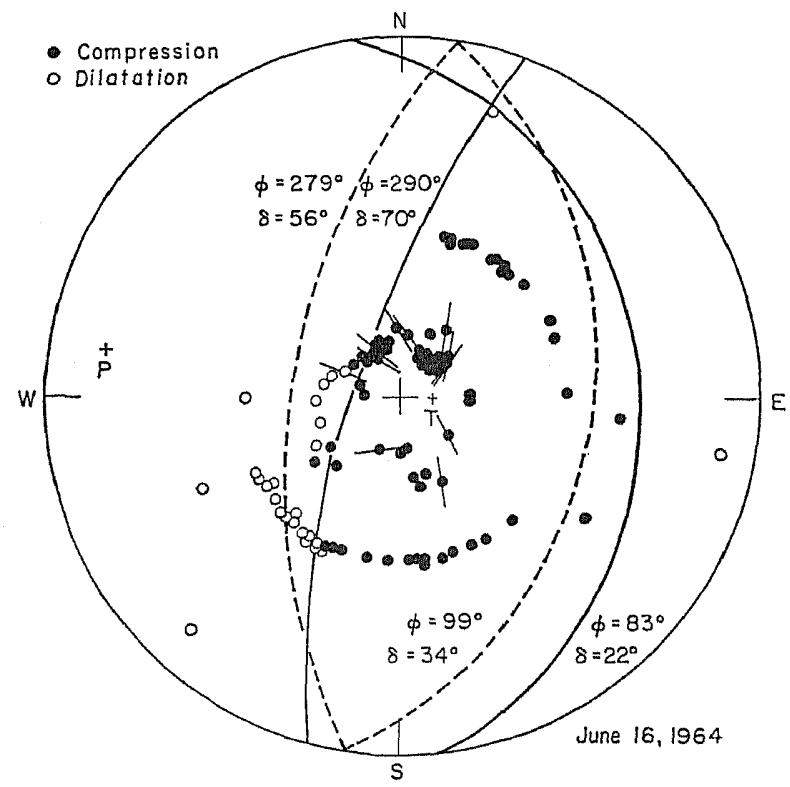

Fig. 3. Stereographic projection (lower hemisphere) of the P wave first motion data and the polarization angles of $S$ waves. The solid curves show the nodal plane solution, Model I, and the broken curves show Model II; $\phi$ is the dip direction measured clockwise from the north and $\delta$ is the dip angle. The crosses with the letter $\mathrm{P}$ and $\mathrm{T}$ show the pressure and tension axes of Model II. 


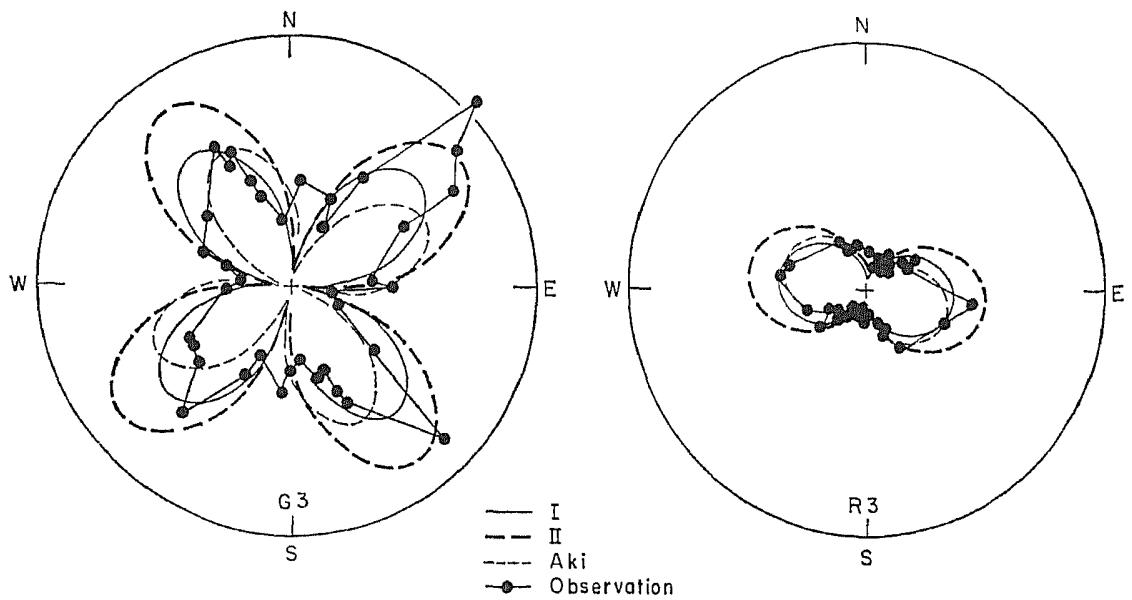

Fig. 4. Surface wave radiation patterns of G3 and R3 for Model I, Model II, and Aki's solution as compared with the observed radiation patterns. The computations are made for a source moment of $5 \times 10^{27} \mathrm{dyne} \cdot \mathrm{cm}$.

distribution of the stations, the second nodal plane cannot be determined (Fig. 3). AKr (1966b) assumed it so as to represent a pure dip-slip motion. The surface wave radiation patterns computed for this geometry are shown in Fig. 4, where we see that the node or loop directions do not coincide with the observations. A superposition of a strike-slip component rotates the nodal directions of surface wave radiation patterns with respect to the strike of the $\mathbf{P}$ wave nodal plane. Accordingly, the above discrepancy can be improved by slightly rotating the second nodal plane. A good fit is obtained for $\phi=38^{\circ}$ and $\delta=22^{\circ}$. This solution is designated Model I (Figs. 3 and 4).

Another body wave data are the polarization angles of $S$ waves. Hirasawa (1965) determined the nodal planes from 12 station data, assuming the focal depth at $33 \mathrm{~km}$. We redetermine the nodal planes using Hirasawa's data and the revised focal depth given in the International Seismological Summary. The hypocenter coordinates used here are: $38.40^{\circ} \mathrm{N}$ (latitude), $139.26^{\circ} \mathrm{E}$ (longitude), and $12 \mathrm{~km}$ (focal depth). The Jeffreys-Bullen travel time and the method described in HrRASAWA (1966) are used. The resultant least-square solution is $\phi=279^{\circ}$ and $\delta=56^{\circ}$ for one nodal plane and $\phi=99^{\circ}$ and $\delta=34^{\circ}$ for another nodal plane. This solution is slightly different from Model I (Fig. 3) and is called Model II. The surface wave radiation patterns for Mode1 II are in good agreement with the observations (Fig. 4). The difference between Model I and II will be discussed later.

For the overall comparison between the observed and synthetic seismograms, we compute the synthetic seismograms G3 and R3 at azimuths of each station. The method and the earth model are identical to those used in 
Kanamori (1970). The results for Model II are given in Figs. 5 and 6. A remarkable similarity between Figs. 1 and 5, and between Figs. 2 and 6 is found. The computations for Model I result in the same conclusion except

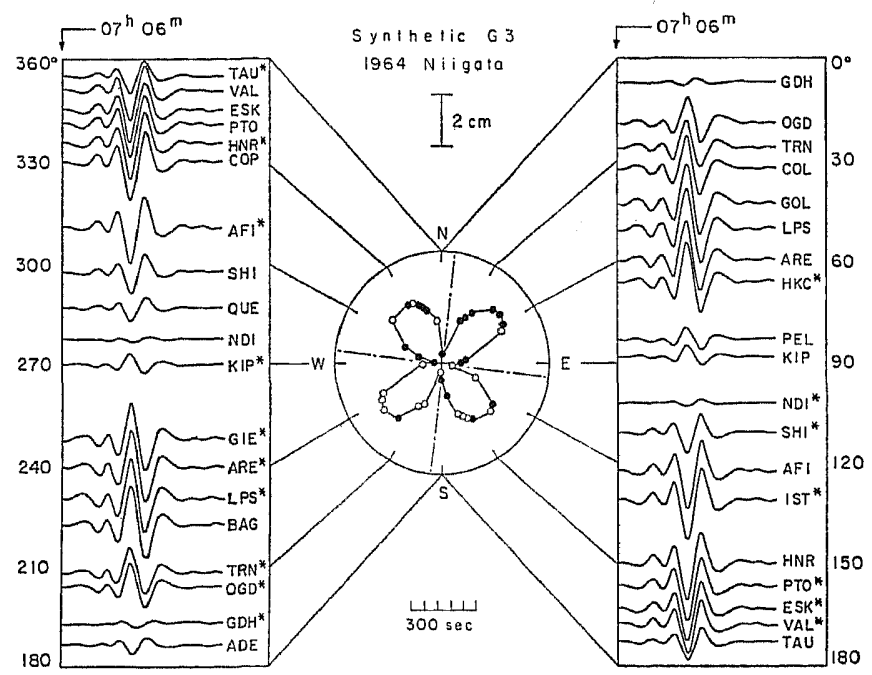

Fig. 5. Synthetic Love waves (G3) to be directly compared with the observed seismograms shown in Fig. 1. The source in a point doublecouple (depth $=33 \mathrm{~km}$ ) with a step source-time function. The computations are made for Model II with a moment of $3.2 \times 10^{27} \mathrm{dyne} \cdot \mathrm{cm}$.

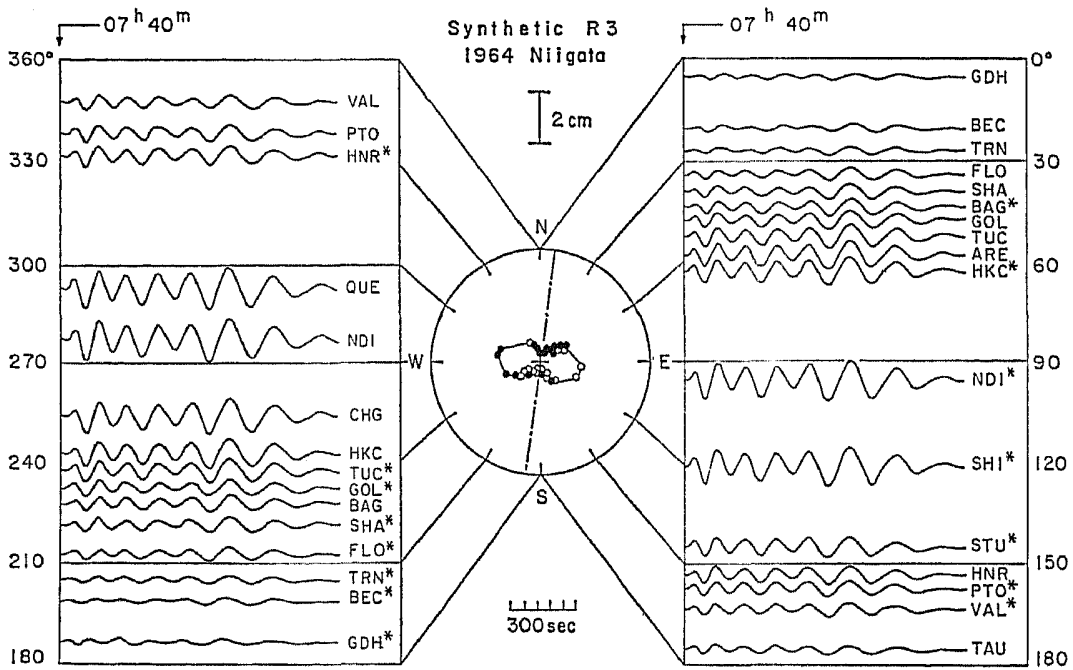

Fig. 6. Synthetic Rayleigh waves (R3) to be directly compared with the observed seismograms shown in Fig. 2. The computations are made for Model II with a moment of $3.2 \times 10^{27}$ dyne. $\mathrm{cm}$. 
for amplitude. From a direct comparison of amplitude between the observed and synthetic seismograms, the seismic moment $M_{0}$ is obtained as $3.2 \times 10^{27}$ dyne.cm $\left(3.2 \times 10^{27}\right.$ for G3 and $3.1 \times 10^{27}$ for R3) for Model II. For Model I, the moment of $4.2 \times 10^{27}$ dyne. $\mathrm{cm}\left(4.1 \times 10^{27}\right.$ for $\mathrm{G} 3$ and $4.2 \times 10^{27}$ for $\left.\mathrm{R} 3\right)$ is obtained.

It is interesting to estimate the seismic moment using the spectral amplitude data of G2 obtained by AKI (1966a). Here it is convenient to arrange the data in conformity with Aki's procedure. The observed values of the equalized spectral densities at a period of $200 \mathrm{sec}$ (Table 6 of AKI, 1966a) are averaged for stations which are located in the azimuthal range of $\pm 20^{\circ}$ around the loop directions. The average for 12 stations is $82 \mathrm{~cm}-\mathrm{sec}$. The corresponding theoretical values are computed for a source moment of $10^{27}$ dyne. $\mathrm{cm}$ (ABE, 1970). The earth model is the same as that used above. The results are $20 \mathrm{~cm}-\mathrm{sec}$ for Model I and $26 \mathrm{~cm}-\mathrm{sec}$ for Model II. Therefore, the moment is estimated as $4.1 \times 10^{27}$ dyne. $\mathrm{cm}$ for Model I and $3.2 \times 10^{27}$ dyne . $\mathrm{cm}$ for Model II. These moments agree with the results derived from $\mathrm{G} 3$ and R3.

\section{Crustal Deformation}

The data on the vertical displacements of the crust associated with the Niigata earthquake are interpreted in terms of a static dislocation model. In order to obtain the appropriate fault parameters, surface displacements are computed for various fault models and compared with the observed data. For the computation we use compact formulations of MANSINHA and SMYLIE (1971).

The fault parameters concerned here are: $\langle D\rangle=$ average slip dislocation along the fault, $L=$ length of the fault, $w=$ width of the fault, and $d=$ depth of the top side of the fault. The average slip dislocation is estimated from $\langle D\rangle=M_{0} / \mu L w$ (AKI, 1966b), where $\mu$ is the rigidity. The rigidity of $4 \times 10^{11}$ dyne $/ \mathrm{cm}^{2}$ is used throughout this study, unless otherwise stated. Some of the other parameters seem to be constrained well by other sets of data. For example, the fault length is well constrained by the aftershock area. As can be seen in Fig. 7, the aftershock area determined accurately by KAYANO (1968, 1973 ) is extended over a distance of $80 \mathrm{~km}$ in the NNE-SSW direction, which nearly coincides with the strike of the nodal planes. The length of the aftershock area is consistent with the rupture length estimated by HIRASAW A (1965). Thus, it is reasonable to constrain the fault length at $80 \mathrm{~km}$. Almost all the aftershocks occurred at depths from the surface to $30 \mathrm{~km}$ (KAYANO, 1968). This also constrains the maximum fault depth in this range. With these constraints, we first interpret levelling data. 


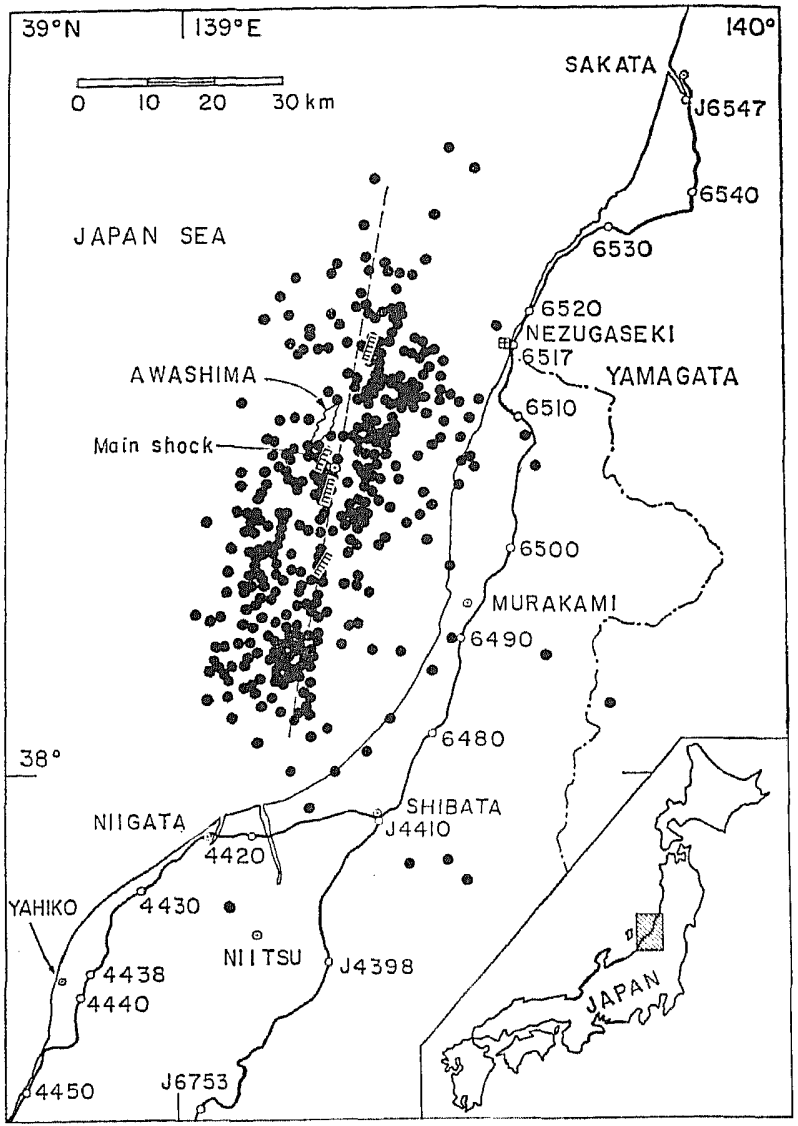

Fig. 7. Distribution of the aftershocks (after KAYANO, 1973). Locations of several bench marks, Awashima Island, Nezugaseki tide station, and Yahiko Crustal Movements Observatory are shown. The line through the epicenter shows the length and the strike of the fault of Model II. The hatched lines show the submarine faults or flexures found by MoGr et al. (1964). The general trend of these segments is consistent with the strike of the main fault.

\subsection{Levelling data}

Along the levelling route on the coast, the Geographical Survey INSTITUTE OF JAPAN $(1966,1970)$ carried out precise levellings before and after the earthquake. Locations of bench marks are shown in Fig. 7. There are about one hundred bench marks over a distance of about $160 \mathrm{~km}$ between bench marks J6547 and 4438.

The surveys were carried out over three segments during different periods (Fig. 8). The junction bench marks are 6475 and A16. The pre- and postseismic deformation is not very large during the periods listed in Fig. 8 (e.g., 


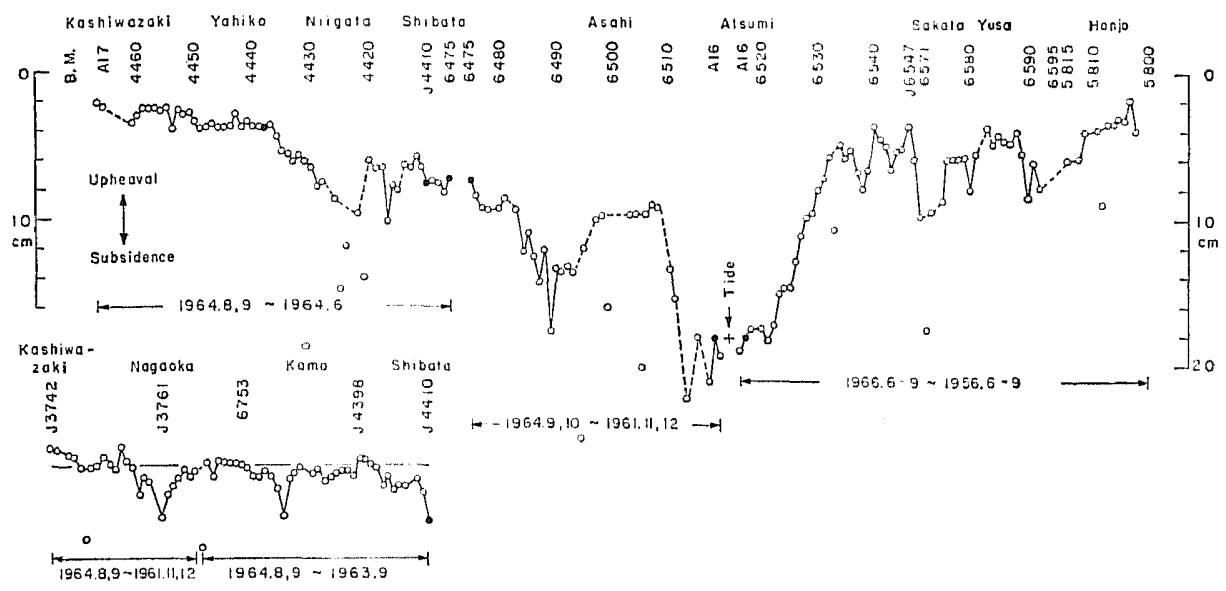

Fig. 8. Levelling data (after Geographical Survey Institute of Japan, 1966, 1970). Locations of the bench marks are shown in Fig. 7. The absolute datum is determined at Nezugaseki tide station.

Dambara, 1973), so that the elevation of the bench marks can be tied simply at these junction points. At the time of the earthquake, Nezugaseki tide station subsided; its amount is estimated to be $18 \mathrm{~cm}$ from the offset of annual mean sea level. This tide station is located very close to bench mark A16. MOGI (1964) surveyed the coast line around Nezugaseki immediately after the earthquake. According to his measurement, the subsidence of Nezugaseki amounts to about $20 \mathrm{~cm}$, which is in good agreement with the tidal offset. On these grounds, the absolute elevation of the bench marks is determined by tying the levelling data to the offset observed in the tidal record. Figure 8 shows all the levelling data thus adjusted. It is seen that the co-seismic deformation is extended over a large area; the general pattern is characterized by a subsidence. The maximum subsidence occurred in the vicinity of Nezugaseki.

The vertical displacements are first computed for the geometry of the steeply dipping nodal plane. In Model $\mathrm{X}$, the fault plane has a dip of $70^{\circ}$ toward $290^{\circ}$, and the fault is a thrust with a right-lateral strike-slip component. In Model $\mathrm{I}$, the earthquake is a reverse dip-slip fault having a dip of $56^{\circ}$ toward $279^{\circ}$.

Displacements for two particular models are first computed for reconnaissance: One is Model I with $w=20 \mathrm{~km}$ and $d=0$; the other is Model II with $w=30 \mathrm{~km}$ and $d=0$. The former model is similar to the model of AKI (1966b). The comparison is given in Fig. 9. For simplicity and clarity, the comparison is made at the twelve data points which are selected from Fig. 8, holding the general pattern of the deformation. It is seen that the resultant displacements are sufficiently different to distinguish between the two models. 


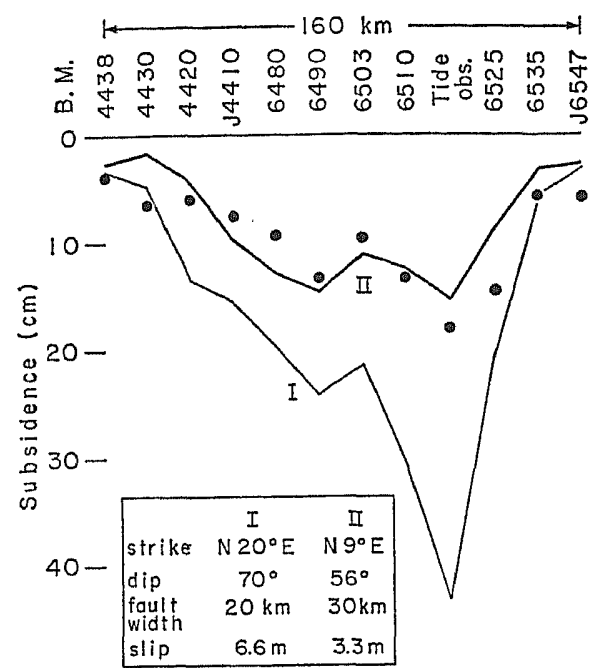

Fig. 9. Comparison of the levelling data with displacements computed for two different fault models. The fault parameters are shown in the inset.

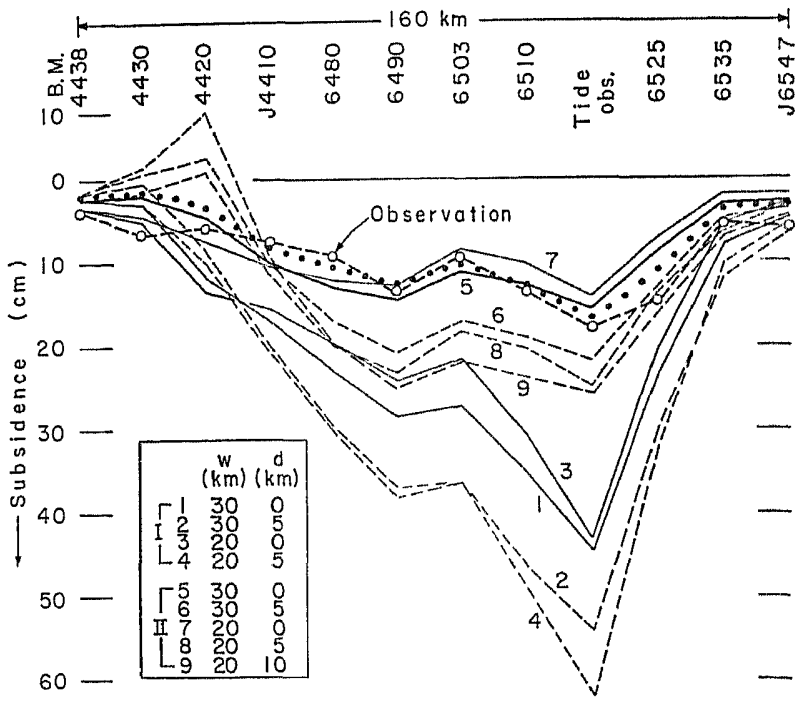

Fig. 10. Comparison of the levelling data with displacements computed for various fault models. The fault parameters and model indexes are shown in the inset, where $w$ is the fault width and $d$ is the depth of the top side of the fault. The fault geometries I and II correspond to steeply dipping nodal planes given in Fig. 3. Closed circles are obtained for a modified model of model 5. 
Encouraged by this successful comparison, we compute displacements for various combinations of source geometry, $w$, and $d$. Several examples are given in Fig. 10 in comparison with the observed data. The model parameters are given in the inset. It is seen that a relatively good fit to the observed data is given by a family of Model II (models 5-9). A family of Model I (models 1-4) yields too large displacements; Model I has a large dip angle and a large dislocation as compared with Model II. Among a family of Model II, models 6,8 , and 9 yield relatively large displacements and local disagreement around bench mark 4420. Aside from the relatively minor difference, models 5 and 7 seem reasonably consistent with the data. Both models are characterized by $d=0$. Since the theoretical displacements are relatively insensitive to $w$, we cannot constrain $w$ at this stage. It is concluded here that the combination of Model II and $d=0$ is preferable.

\subsection{Upheaval at Awashima Island}

In order to determine the remaining source parameter, we introduce other data. A small island, Awashima, located about $8 \mathrm{~km}$ north of the epicenter, was upheaved at the time of the earthquake. According to the habitants, the level of the sea was lowered more than $2 \mathrm{~m}$ at the time of the earthquake, the suggestion being that the co-seismic upheaval could be more than $2 \mathrm{~m}$ (NaKamura et al., 1964). However, confirmation of this report seems very difficult, since the tsunami may have disturbed the sea level at the same time. Nakamura et al. (1964) concluded, on the basis of a biological mark on the coast and the sea level, that the island was upheaved by 80 to $160 \mathrm{~cm}$ and tilted 56" to the west. We use this data, bearing in mind that the amount would be subject to some uncertainty.

The displacements are plotted in Fig. 11 for a section normal to the fault strike passing through Awashima. The model parameters are given in Fig. 10. All the theoretical displacements are not completely consistent with the Awashima data. However, among them model 5 seems still tolerable in view of the uncertainty of the data and the gross simplification made in the dislocation model of the fault. Although model 7 is similar to model 5, its displacements are too large compared with the observed data. Thus, model 5 is much more adequate than model 7. Model 5 has the fault width of $30 \mathrm{~km}$.

The slight disagreement between model 5 and Awashima data can be improved in several ways. If we assume $\mu=6 \times 10^{11} \mathrm{dyne} / \mathrm{cm}^{2}$ instead of $4 \times$ $10^{11}$, the theoretical displacements are reduced by $30 \%$. This case is shown in Fig. 11 by the solid circles. The similar improvement can be obtained by considering inhomogeneous distribution of the dislocation. One of the simple cases is the composite fault which consists of one northern fault segment $(L=15 \mathrm{~km})$ with a dislocation of $6.6 \mathrm{~m}$ and the other fault segment $(L=65 \mathrm{~km})$ 


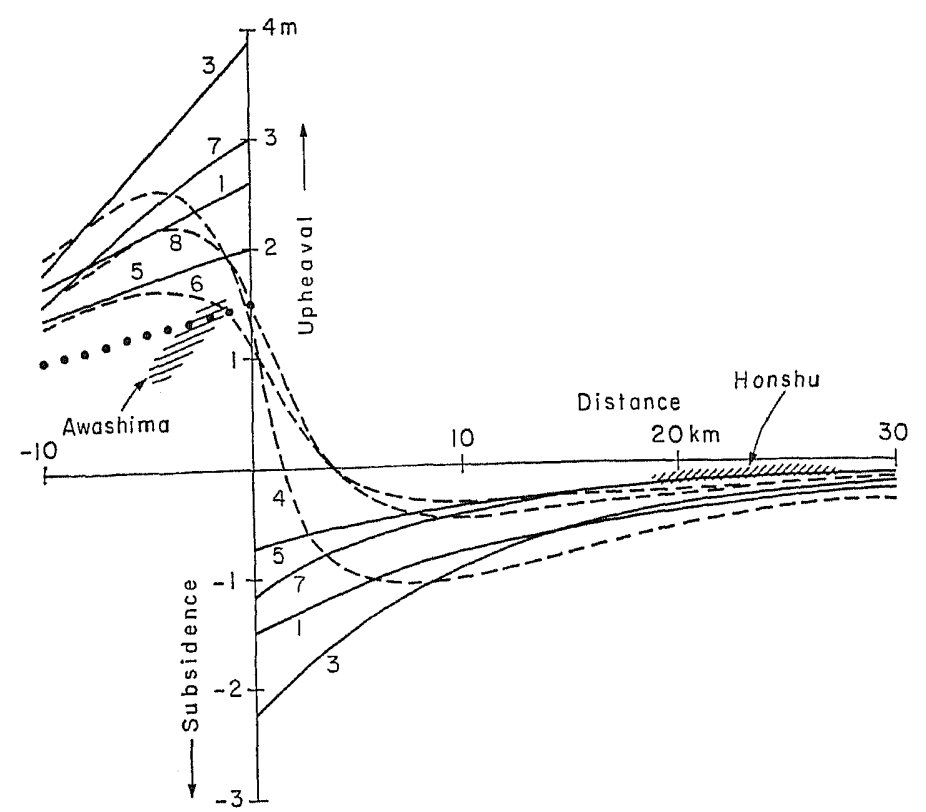

Fig. 11. Comparison of the observed vertical displacements with displacements computed for various fault models. The model indexes are explained in the inset of Fig. 10. Closed circles are obtained for a modified model of model 5 .

with a dislocation of $2.5 \mathrm{~m}$. This model does not change the seismic moment. This composite fault model gives the similar result (solid circles in Fig. 11). The displacements for this model are also shown in Fig. 10 by solid circles. A slight improvement is seen. Despite their plausibility, however, these improvements are more or less artificial and in no way unique, unless observational data over a wider area are available. In addition, a homogeneous structure of the crust made in the computation may not be adequate to explain the details of the data, and the crustal deformation data are generally subject to the uncertainty as mentioned before. In view of these, we prefer the simple but reasonable model 5 .

The displacements were computed, in much the same way, for the gently dipping nodal planes of both Model I and II. Although these cases are not shown, the resultant displacements were incompatible in sense and magnitude with Awashima and Honshu data. This examination leads to a conclusion that the fault plane of this earthquake is the steeply dipping plane, not the one dipping slightly.

\subsection{Tilt measurement}

A tiny tilt-step was observed by the two-component water-tube tiltmeters 
at Yahiko. The observed tilt-step is $0.18^{\prime \prime}$ dipping toward N4 ${ }^{\circ} \mathrm{E}$ (YAHIKo Crustal Movements Observatory, 1973). The observatory is located about $50 \mathrm{~km}$ southwest of the fault tip (Fig. 7), where weak concentration of stress could have occurred (Chinnery, 1963; MARUyama, 1969). The dislocation model with a constant slip appears to be applicable to the present case, since the singular region around the fault tip is probably confined to a comparatively small region in the immediate neighborhood of the fault (e.g., CHINNERY and PeTRAK, 1968).

The theoretical steps computed for several fault models are compared with the observation in Fig. 12. The model parameters are given in Fig. 10.

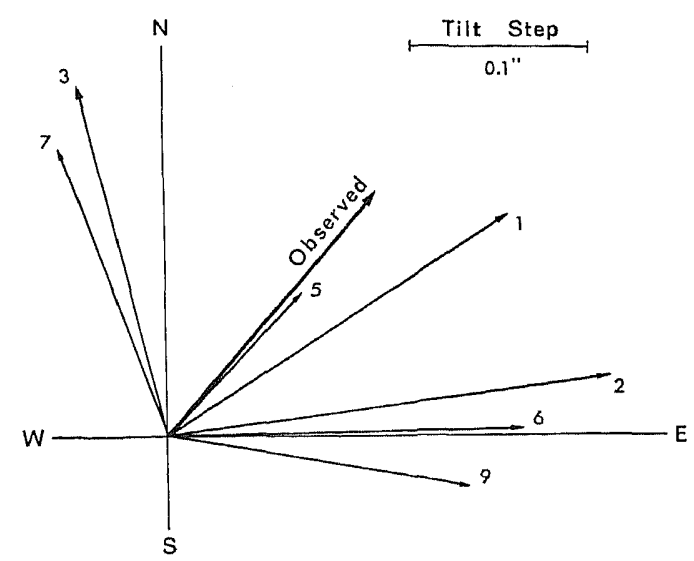

Fig. 12. Comparison of the tilt step observed at Yahiko with tilt steps computed for various fault models. The model indexes are explained in the inset of Fig. 10.

It is seen that the directions of the theoretical steps are very sensitive to the model parameters. Both magnitude and direction for model 5 are still in satisfactory agreement with the observation; the calculated step is $0.11^{\prime \prime}$ dipping toward $\mathrm{N} 43^{\circ} \mathrm{E}$. Model 7 is found to be incompatible with the observation. Therefore, model 5 is adequate for representing the earthquake fault.

We reach the conclusion that the crustal deformation data associated with the Niigata earthquake are interpreted well in terms of a pure dip-slip fault reaching the earth's surface and having a dip of $56^{\circ}$ toward $\mathrm{N} 81^{\circ} \mathrm{W}$, a dimension of $80 \mathrm{~km}$ (length) $\times 30 \mathrm{~km}$ (width), and an average dislocation of $3.3 \mathrm{~m}$. The vertical and horizontal displacements expected of this fault model are shown in Fig. 13, and the vertical displacements are shown in Fig. 9 in comparison with the levelling data. 


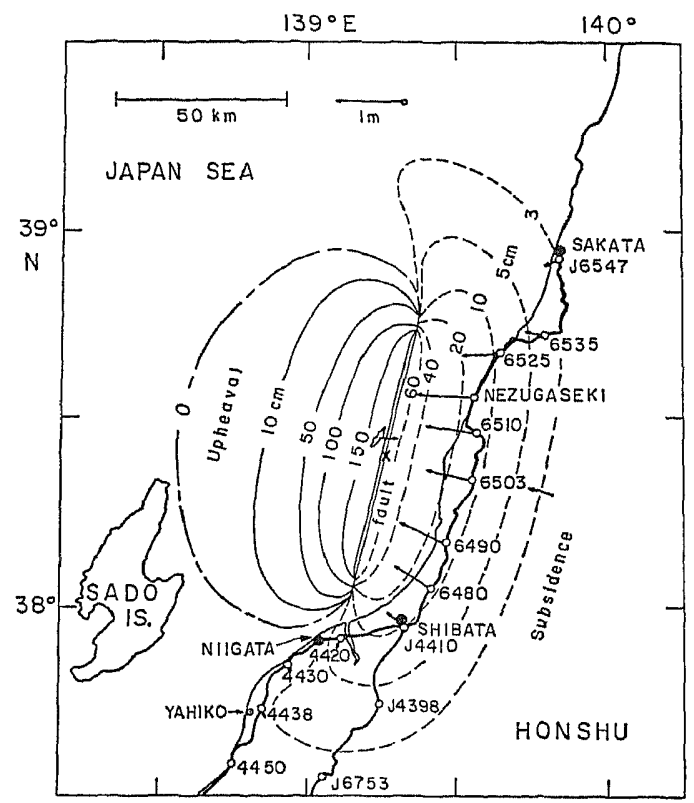

Fig. 13. Vertical (contour lines) and horizontal (arrows) displacements calculated for the best model (model 5) for the Niigata earthquake of 1964.

\section{Discussion and Conclusion}

In the computations of synthetic surface waves, we ignored the effect of a finite rupture propagation. A rupture propagation affects the amplitudes of surface waves, but the effect can be estimated to be very small, less than $10 \%$ in the present case; the Niigata earthquake is a bilateral rupture with a rupture velocity of $2-3 \mathrm{~km} / \mathrm{sec}$ (HIRASAWA, 1965; FuKAO, 1974). Thus removal of the assumption of the point source does not greatly affect the seismic moment estimated here.

The seismic moment of Model II agrees with the value of $3 \times 10^{27}$ dyne. $\mathrm{cm}$ estimated by AKI (1966b). However, this agreement is somewhat fortuitous because different source geometries were used. The moment of Model I should be compared with Aki's result. A close inspection of Fig. 1 of AKI (1966b) reveals that the moment of Aki's model must be around $4 \times 10^{27} \mathrm{dyne}$. $\mathrm{cm}$ over the period range from 100 to $200 \mathrm{sec}$. It is logical that this moment is in turn in good agreement with the moment of Model $\mathrm{I}$.

The Model I is not reconciled with the geodetic data, while the similar model, Model II, reasonably explains the geodetic data. The implication of this fact is very interesting in view of the faulting process. We note that longperiod $\mathrm{P}$ waves at the WWSSN stations consist of several phases. According 
to Hirasawa (1965), the first phase to give the first motion data has very small amplitude with a weak beginning, and the second phase, mostly about $4 \mathrm{sec}$ after the onset, has large amplitude with a jerky compressional motion at every teleseismic station. Although HIRASAWA (1965) attempted to interpret the second phase in terms of $\mathrm{pP}, \mathrm{sP}$, and breakout phases, its interpretation seems difficult in the amplitude. Considering this unusual initial behavior, we may interpret the entire faulting process in terms of a multiple faulting. The whole sequence may be pictured as follows. The initial fault break begins with a geometry like Model I at the hypocenter and propagates. The propagation distance is roughly estimated as about $10 \mathrm{~km}$ or smaller from the duration time of the first phase and rupture velocity of 2 to $3 \mathrm{~km} / \mathrm{sec}$. About $4 \mathrm{sec}$ after the initial break, the major faulting takes place over the remaining entire fault plane with a geometry of Model II, which is responsible for the excitation of long-period surface waves and the crustal movements. This model is not inconsistent with the result that the $\mathrm{S}$ wave solution is consistent with the surface wave radiation patterns; the polarization angles would have been determined from $S$ waves of the catastrophic event by inevitably missing $S$ waves of the small initial event. Although this simple model is not a unique one, it explains the observed sequence in a consistent manner. Similar change in faulting geometry has been reported for the San Fernando earthquake of 1971 (HANKs, 1974; Jungels and Frazier, 1973).

Using the fault parameters of model 5 , we can estimate the vertical displacement which is responsible for the tsunami generation (ABE, 1973). The displacement is computed to be $140 \mathrm{~cm}$. This value is found to be consistent with the observed height of the sea-level disturbance averaged over the tsunami source area, considering unavoidable large uncertainties in the tsunami data; HATORI (1965) estimated it as $180 \mathrm{~cm}$ from the tsunami heights observed on the coast. Although more detailed discussions may be found in ABE (1973), the above agreement indicates that the tsunami was set off by the deformation of the sea bottom predicted by the model 5 .

Since various fault parameters have been obtained, the stress drop and released strain energy can be readily estimated according to the 2-dimensional crack theory of faults (AKI, 1966b). The results are: stress drop, 75 bars; strain drop, $1.9 \times 10^{-4}$; strain energy $3.0 \times 10^{23} \mathrm{erg}$. A penny-shaped crack model (KEYLIS-BoroK, 1959) gives the stress drop of 66 bars and the strain energy of $2.6 \times 10^{23} \mathrm{erg}$. Despite the uncertainties in the mathematical modeling of faults, the above result indicates that the stress drop is about 70 bars. This value is about $3 / 5$ of the previous estimate by AKI (1966b), and is not very different from the stress drops obtained for moderate to large shallow earthquakes which occurred in the Japanese islands.

The successful re-determination of the stress drop enables a reliable esti- 
mate of the dislocation velocity. According to ABE (1975), the dislocation velocity is proportional to the stress drop in major earthquakes which occurred in the Japanese islands. Using the empirical relation for Japan, the dislocation velocity for the Niigata earthquake is estimated as $70 \mathrm{~cm} / \mathrm{sec}$. The corresponding rise time, which represents the time required for the completion of the dislocation at a point on the fault, is estimated to be $5 \mathrm{sec}$. Although these values may be subject to large uncertainty because of the indirect estimate, these would be useful as a guiding value for earthquake engineering purposes.

The fault parameters of the Niigata earthquake of 1964 re-determined on the basis of the data on the body wave, surface wave, aftershock, levelling, and some other geodetic data are summarized as follows: source geometry, double-couple reverse dip-slip; strike, $\mathrm{N} 9{ }^{\circ} \mathrm{E}$; dip, $56^{\circ}$ toward $\mathrm{N} 81^{\circ} \mathrm{W}$; seismic moment, $3.2 \times 10^{27} \mathrm{dyne} \cdot \mathrm{cm}$; fault length, $80 \mathrm{~km}$; fault width, $30 \mathrm{~km}$; average dislocation, $3.3 \mathrm{~m}$; stress drop, $70 \mathrm{bars}$; strain drop, $1.8 \times 10^{-4}$.

I am grateful to Dr. Keiiti Aki for providing me with the seismograms he collected and for kindly reviewing the manuscript. This work was partially supported by The Advanced Research Projects Agency monitored by the Air Force Office of Scientific Research under Contract F44620-71-C-0049.

\section{REFERENCES}

AвE, K., Determination of seismic moment and energy from the earth's free oscillation, Phys. Earth Planet. Inter., 4, 49-61, 1970.

ABE, K., Focal process of the South Sandwich Islands earthquake of May 26, 1964, Phys. Earth Planet. Inter., 5, 110-122, 1972a.

AвE, K., Lithospheric normal faulting beneath the Aleutian trench, Phys. Earth Planet. Inter., 5, 190-198, 1972b.

ABE, K., Mechanisms and tectonic implications of the 1966 and 1970 Peru earthquakes, Phys. Earth Planet. Inter., 5, 367-379, $1972 \mathrm{c}$.

ABE, K., Tsunami and mechanism of great earthquakes, Phys. Earth Planet. Inter., 7, 143-153, 1973.

ABE, K., Static and dynamic parameters of the Saitama earthquake of July 1, 1968, Tectonophysics, 27, 223-238, 1975.

Akr, K., Generation and propagation of $G$ waves from the Niigata earthquake of June 16, 1964. Part 1. A statistical analysis, Bull. Earthq. Res. Inst. Tokyo Univ., 44, 23-72, 1966 a.

AkI, K., Generation and propagation of $G$ waves from the Niigata earthquake of June 16 , 1964. Part 2. Estimation of earthquake moment, released energy, and stress-strain drop from the G wave spectrum, Bull. Earthq. Res. Inst. Tokyo Univ., 44, 73-88, $1966 \mathrm{~b}$.

CHINnEry, M. A., The stress changes that accompany strike-slip faulting, Bull. Seismol. Soc. Amer., 53, 921-932, 1963.

Chinnery, M.A. and J.A. Petrak, The dislocation fault model with a variable discontinuity, Tectonophysics, 5, 513-529, 1968.

Dambara, T., Crustal movements before, at, and after the Niigata earthquake, Rep. Coord. Comm. Earthq. Prediction, Geogr. Surv. Inst. Japan, 9, 93-96, 1973 (in Japanese). 
Earthquake Research Institute, Survey report of the Niigata earthquake, Spec. Bull. Earthq. Res. Inst. Tokyo Univ., 8, 1-133, 1964 (in Japanese).

Fukao, Y., Analysis of near-distance surface waves of the Niigata earthquake, Abstract for Ann. Meet. Seismol. Soc. Japan, 1974 (in Japanese).

Geographical Survey Institute of Japan, Collection of Results of Precise Levels along Primary Bench Marks, No. 41-10, 1966.

Geographical Survey Institute of JAPan, Investigation of the Crustal Deformation in the Niigata District, pp. 93, 1970.

HANks, T. C., The faulting mechanism of the San Fernando earthquake, J. Geophys. Res., 79, $1215-1229,1974$.

Hatori, T., On the tsunami which accompanied the Niigata earthquake of June 16, 1964, Source deformation, propagation and tsunami run-up, Bull. Earthq. Res. Inst. Tokyo Univ., 43, 129-148, 1965.

Hirasawa, T., Source mechanism of the Niigata earthquake of June 16, 1964, as derived from body waves, J. Phys. Earth, 13, 35-66, 1965.

Hirasawa, T., A least squares method for the focal mechanism determination from $\mathrm{S}$ wave data: Part 1, Bull. Earthq. Res. Inst. Tokyo Univ., 44, 901-918, 1966.

Japan Meteorological Agency, Survey report of the Niigata earthquake, Tech. Rep. Japan Meteorol. Agency, 43, 1-230, 1965 (in Japanese).

Jungels, P. H. and G. A. Frazier, Finite element analysis of the residual displacements for an earthquake rupture: Source parameters for the San Fernando earthquake, J. Geophys. Res., 78, 5062-5083, 1973.

KANAMORI, H., Synthesis of long-period surface waves and its application to earthquake source studies-Kurile Islands earthquake of October 13, 1963, J. Geophys. Res., 75, 50115027, 1970.

KANAMORI, H., Focal mechanism of the Tokachi-Oki earthquake of May 16, 1968: Contortion of the lithosphere at a junction of two trenches, Tectonophysics, 12, 1-13, 1971.

Kawasumi, H. (ed.), General Report on the Niigata Earthquake, pp. 550, Tokyo Elect. Eng. Col. Press, Tokyo, 1968.

Kayano, I., Determination of origin times, epicenters and focal depths of aftershocks of the Niigata earthquake of June 16, 1964: A preliminary report of the cooperative study of aftershocks of the Niigata earthquake, Bull. Earthq. Res. Inst. Tokyo Univ., 46, 223-269, 1968.

Kayano, I., Several problems on the hypocenter determination of local earthquakes, Spec. Bull. Earthq. Res. Inst. Tokyo Univ., 12, 83-98, 1973 (in Japanese).

Keylrs-Borok, V., On estimation of the displacement in an earthquake source and of source dimensions, Ann. Geofis., 12, 205-214, 1959.

Mansinha, L. and D. E. Smylie, The displacement fields of inclined faults, Bull. Seismol. Soc. Amer., 61, 1433-1440, 1971.

Maruyama, T., Stress fields in the neighborhood of a crack, Bull. Earthq. Res. Inst. Tokyo Univ., 47, 1-29, 1969.

Mogr, K., Deformation at the coast of Murakami and Kamo, Spec. Bull. Earthq. Res. Inst. Tokyo Univ., 8, 46-51, 1964 (in Japanese).

Mogi, A., B. Kawamura, and Y. Iwabuchi, Submarine crustal movement due to the Niigata earthquake in 1964, in the environs of the Awa Sima Island, Japan Sea, J. Geod. Soc. Japan, 10, 180-186, 1964.

Nakamura, K., K. Kasahara, and T. Matsuda, Tilting and uplift of an island, Awashima, near the epicenter of the Niigata earthquake in 1964, J. Geod. Soc. Japan, 10, 172-179, 1964. 
Scholz, C. H., L. R. Sykes, and Y. P. Aggarwal, Earthquake prediction: A physical basis, Science, 181, 803-810, 1973.

TsuboKawa, I., Y. OGAWA, and T. HAYASHI, Crustal movements before and after the Niigata earthquake, J. Geod. Soc. Japan, 165-171, 1964.

YAhiko CRUSTAL Movements ObSeRvatory, Crustal movements in the Sado-Yahiko district (II), Rep. Coord. Comm. Earthq. Prediction, Geogr. Surv. Inst. Japan, 9, 79-85, 1973 (in Japanese). 